\title{
Main complications of rotational atherectomy: a nursing point of view with 3-step protocol
}

\section{(1) Marija Romić*, (i)Tea Galić, (D)Andrija Matetić}

University Hospital Centre Split, Split, Croatia
RECEIVED:

February 18, 2020

ACCEPTED:

February 22, 2020

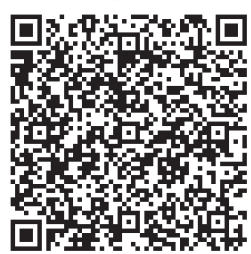

KEYWORDS: rotational atherectomy, complications, nursing protocol.

CITATION: Cardiol Croat. 2020;15(3-4):69. | https://doi.org/10.15836/ccar2020.69

*ADDRESS FOR CORRESPONDENCE: Marija Romić, KBC Split, Spinčićeva 1, HR-21000 Split, Croatia. / Phone: +38597-6151-277 / E-mail: marijaromic31@gmail.com

ORCID: Marija Romić, https://orcid.org/0000-0002-7683-2837 • Tea Galić, https://orcid.org/0000-0001-6218-3314

Andrija Matetić, https://orcid.org/0000-0001-9272-6906

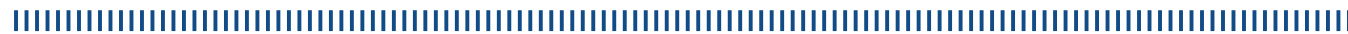

Rotational atherectomy (RA) is a type of percutaneous coronary intervention used to treat severely calcified coronary stenoses. While it offers a great therapeutic modality for complex coronary lesions, its complications could be devastating. Therefore, excellent theoretical knowledge of the possible complications and subsequent therapeutic approach by the entire interventional team is crucial for the successful procedure. ${ }^{1-3}$

Here we introduce our 3-step nursing protocol for the main RA complications: 1. Preventive phase: The prevention of complications relies on adequate communication of the interventional team, competent equipment preparation (including flushing drug cocktail) and device set-up. Attention to timely raise concerns using a well-established PACE method (Probe, Alert, Challenge, Emergency) if the patient safety issues are endangered is crucial. Preprocedural system testing using a well-established DRAW method, understanding of the optimal RA technique and the potential rotablator system failure, as well as cautious ECG/angiogram monitoring is of high importance. 2. Emergency management phase: Supportive atmosphere, teamwork and effective communication with a feedback loop is crucial for successful management of complications. - Slow flow phenomenon: venous access re-assessment; preparation of BP optimization therapy; assistance in continuous ECG and BP monitoring; anticipation of pharmacologic therapy administration - Coronary dissection: adequate RA equipment withdrawal; assistance in wire position maintenance; preparation of angioplasty balloon and stent panel - Coronary perforation: warn an interventional team if on-going anticoagulation therapy; preparation of BP optimization therapy; adequate RA equipment withdrawal; assistance in wire position maintenance; continuous angiographic re-assessment of the perforation; preparation of angioplasty balloon, cover stent and coil panel; anticipation of emergent pericardiocentesis. 3. Follow-up phase - Clear communication with the nurse colleagues using a well-established SBAR communication model (Situation, Background, Assessment, Recommendation) - Reassessment of all procedural issues in the nursing reports including therapy and patient data.

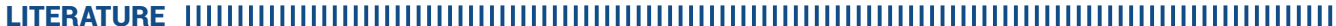

1. Tomey MI, Kini AS, Sharma SK. Current status of rotational atherectomy. JACC Cardiovasc Interv. 2014 Apr;7(4):345-53. https://doi.org/10.1016/j.jcin.2013.12.196

2. Gupta T, Weinreich M, Greenberg M, Colombo A, Latib A. Rotational Atherectomy: A Contemporary Appraisal. Interv Cardiol. 2019 Nov 18:14(3):182-189. https://doi.org/10.15420/icr.2019.17.R1

3. Barbato E, Carrié D, Dardas P, Fajadet J, Gaul G, Haude M, et al; European Association of Percutaneous Cardiovascular Interventions. European expert consensus on rotational atherectomy. EuroIntervention. 2015 May;11(1):30-6. https://doi.org/10.4244/EIJV1111A6 